\title{
OAC and SAC Perspectives on Massachusetts Ocean Management Plan Performance
}

Prepared by:

Dave Kellam

Stephanie Moura

Kim Starbuck

April 2013

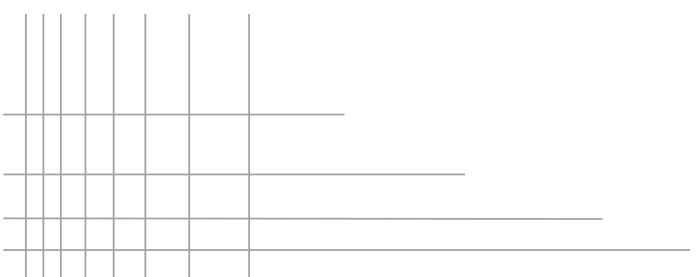




\section{ABSTRACT}

In 2013, the Massachusetts Office of Coastal Zone Management (MA CZM) undertook an assessment of the 2009 Massachusetts Ocean Management Plan (Plan) in preparation for a Plan Amendment. As one phase of the Plan Assessment process, MA CZM coordinated with SeaPlan to conduct semi-structured interviews with members of the Massachusetts Ocean Advisory Commission (OAC) and Massachusetts Ocean Science Advisory Council (SAC) to assess their perspectives on Plan performance. Interviewers from SeaPlan's assessment team contacted advisors and asked questions about the Plan, focusing on the Plan's development process, the Plan's implementation and recommendations for a future amendment to the Plan. The assessment team coded and analyzed responses to identify perspectives and insights held by OAC and SAC members. Overall, OAC and SAC members were very satisfied with the CZM staff's competency to develop the 2009 Plan and the staff's administrative execution. OAC and SAC members appreciated the focused effort to produce a quality plan specific to Massachusetts' habitats, economy, and stakeholders. Results of this assessment, coupled with a review of the Massachusetts Ocean Management Plan conducted by CZM, provides valuable context and insight for the plan amendment process.

\section{ACKNOWLEDGEMENTS}

SeaPlan wishes to thank Dr. Verna DeLauer of Clark University for advice on data analysis for this assessment; the staff of MA CZM for for helping coordinate the interviews and providing input in the interview design; and the members of the $\mathrm{OAC}$ and SAC for their participation in the study.

\section{Authors:}

Dave Kellam, SeaPlan

Stephanie Moura, SeaPlan

Kim Starbuck, SeaPlan

April 2013

\section{Recommended Citation:}

Kellam, D., Moura, S., \& Starbuck, K., OAC and SAC Perspectives on Massachusetts

Ocean Management Plan Performance, 2013, SeaPlan, Boston, MA

This report may be downloaded at www.SeaPlan.org/projects

This work is funded by the Gordon and Betty Moore Foundation.

(C) SeaPlan - April, 2013 doc\#315.01.13

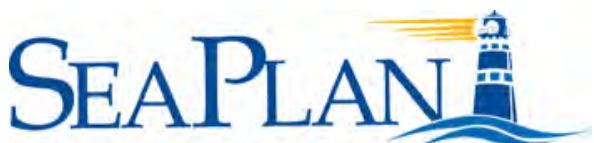

VIBRANT ECONOMIES - HEALTHY OCEANS

SeaPlan

89 South Street

Boston MA 02111

www.SeaPlan.org 


\section{Contents}

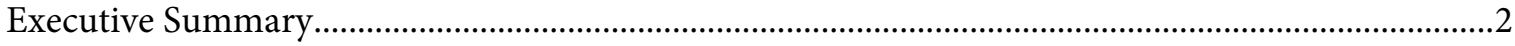

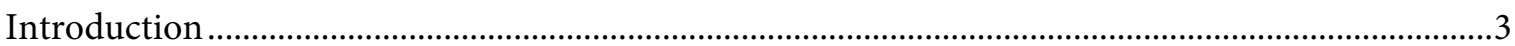

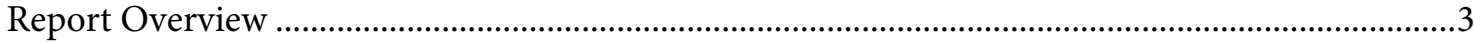

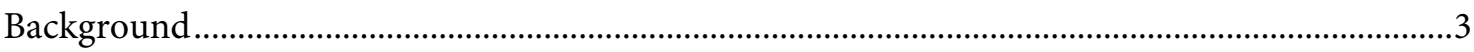

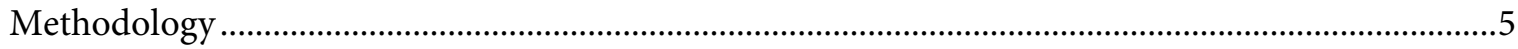

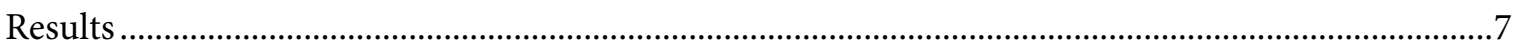

SLICE ONE: Responses by Questions ............................................................................................

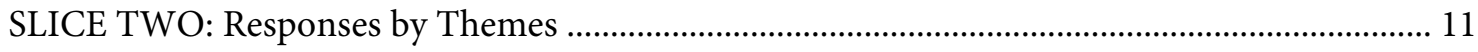

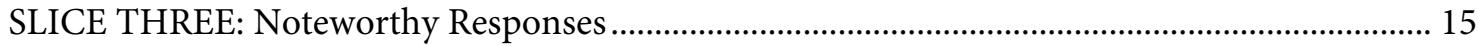

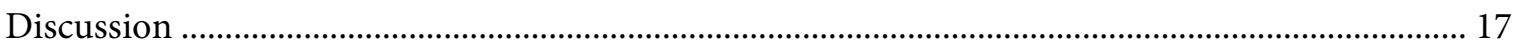

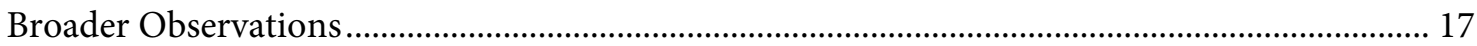

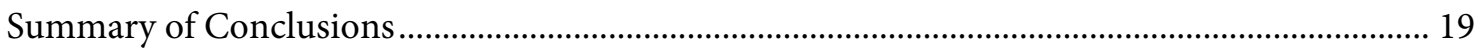

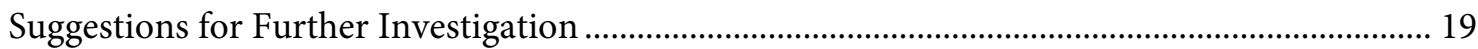

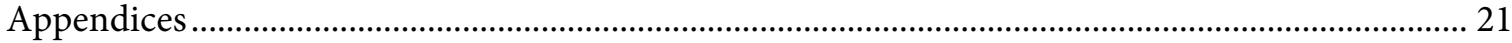

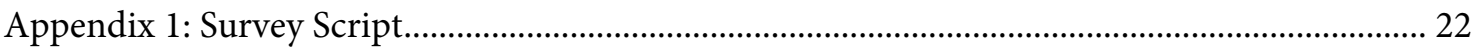

Appendix 2: Complete List of Theme Codes..................................................................................... 24

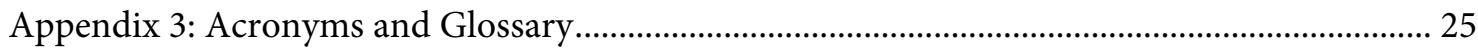




\section{Executive Summary}

To assess the performance of the 2009 Massachusetts Ocean Management Plan and prepare for initiating the first formal Plan revision in 2014, the Massachusetts Office of Coastal Zone Management (CZM) undertook a review of the Plan in 2012-13. As a component of this review SeaPlan - an independent nonprofit ocean science and policy group - conducted a formative evaluation using semi-structured interviews of current and previous members of the Ocean Advisory Commission (OAC) and the Ocean Science Advisory Council (SAC) about their perspectives on Plan development, implementation and future revision.

The SeaPlan team designed the study, conducted OAC and SAC interviews, and compiled and analyzed responses. The data reveal certain shared perceptions and themes among advisory members and other noteworthy, though less widely held, reflections. Overall, OAC and SAC members were very satisfied with CZM staff competency to conduct marine spatial planning and the staffs administrative execution. OAC and SAC members appreciated the focused effort to produce a quality plan responsive to the specific Massachusetts context.

The table below provides a brief overview of findings based on OAC and SAC perceptions about Plan performance and future revisions. The body of the report describes the methodology in greater detail and presents a thorough discussion of the team's findings. The assessment concludes with suggestions for further research to evaluate Plan performance and improve the revision process.

\section{Summary of Findings}

OAC and SAC members appreciated the focused effort by CZM and partners to produce a quality plan responsive to specific Massachusetts conditions. Most members were keenly aware of the Plan's significance as the first plan of its kind in the nation and a model for other regions.

OAC and SAC members view CZM staff as very competent. OAC Commissioners and SAC Councilors are generally very satisfied with the Plan development and implementation.

Plan implementation and performance is gauged primarily in terms of permitting outcomes, rather than administrative progress or progress on science and data priorities.

Administrative execution and communication during the planning process were seen as effective and attributable largely to the time-limited context for Plan development. Maintaining an intense focus and engagement will be challenging as the Plan transitions from development to routine implementation.

Key issues of interest to OAC and SAC members for the Plan revision process include: climate change adaptation issues, further goals and indicators development, and integration with regional CMSP efforts.

$\mathrm{OAC}$ and SAC meeting structure and schedule is generally adequate, although certain improvements were suggested, including clearer communication of meeting objectives, longerrange scheduling, and increased interactions between the OAC and SAC through more intragroup and inter-group communications. There was limited interest in conducting meetings through a webinar. 


\section{Introduction}

\section{Report Overview}

This report begins with the background and impetus for this assessment, a description of the interview subjects and justification for the assessment approach. The Methodology section includes the research questions, the interview protocol, and a characterization of the assessment team. In the Results section, the interview data are presented in the three different ways, or "slices". The first slice organizes responses by question, in the order that they were asked in the interview script (Appendix 1). This shows how interviewees answered specific questions and is especially useful for summarizing close-ended questions. The second slice organizes the data using a cross-cut filter of themes identified in responses. This common qualitative research approach helps illustrate the overarching themes noted by interviewees during their discussion of the Plan. The third slice highlights noteworthy insights, which are responses made by one or two interviewees that the SeaPlan assessment team believe warrant acknowledgement based on the team's collective knowledge of marine spatial planning and first-hand experience with the Plan development process. The Discussion section includes the assessment team's broader observations from the interview data, a table of conclusions and potential areas for further investigation.

\section{Background}

As part of the "Review of the Massachusetts Ocean Management Plan" (Review) conducted by CZM, SeaPlan - an independent nonprofit ocean science and policy group - conducted a formative evaluation of the Plan using semi-structured interviews of current and previous members of the $\mathrm{OAC}$ and SAC about their attitudes on Plan development and implementation. This third-party assessment was intended to strengthen the Review by providing various perspectives on the strengths of the Plan process and suggestions for improvement from those directly involved in an advisory capacity. The assessment team's analysis of the interview data will likely help inform a future revision process to be conducted by CZM.

To enrich the Review, SeaPlan coordinated with CZM and conducted a semi-structured interview with the majority of OAC and SAC members regarding plan development, implementation, updating and possible refinements to the revision process (Figure.1). The analysis of the OAC and SAC interviews will be included in the Review published by MA CZM. The semi-structured interview method is well-suited for this assessment because it focused conversations with OAC and SAC members enough to garner specific feedback on key issues while encouraging an open dialogue and the possibility for discovery of issues and noteworthy insights. 
The SeaPlan assessment team recommended a formative evaluation, which is a type of assessment that takes place before or during a program's implementation with the aim of improving the program's design and performance. ${ }^{1} \mathrm{~A}$ formative evaluation complements a summative evaluation that focuses on outcomes rather than process. Formative evaluations helps managers understand why a program works or doesn't, and what other factors (internal and external) could influence program effectiveness. Triangulating SeaPlan's qualitative interview data with the systematic Review by CZM will create a rich understanding of the Plan process and areas for improvement (see Figure 1).

Figure 1: Triangulation of Assesment for Review of the Massachusetts Ocean Management Plan

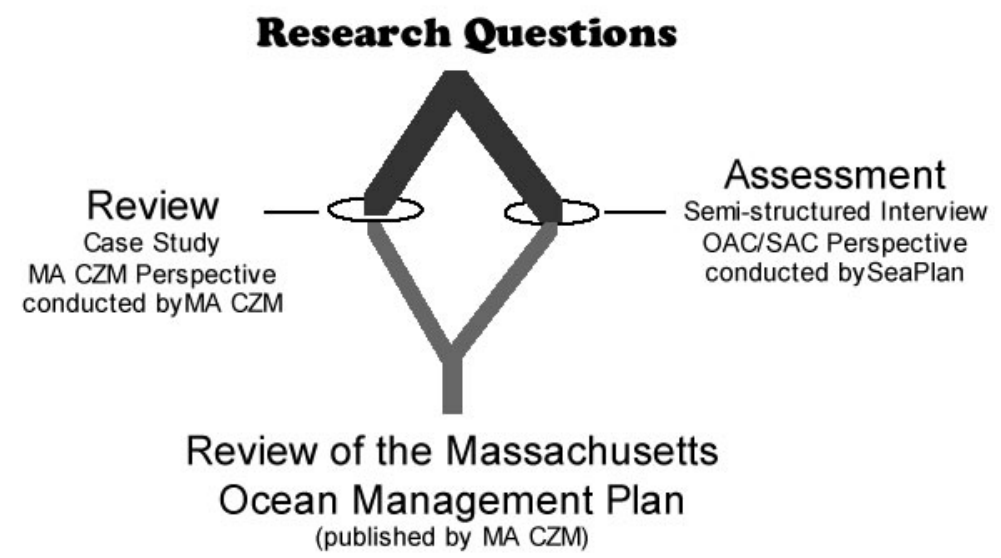

Given the experience and expertise of the OAC and SAC members, as well as their knowledge of local and state issues, the assessment team believed their opinions would be extremely valuable to help guide CZM during the assessment and revision process. Furthermore, SeaPlan's neutral status during this assessment enabled OAC and SAC members to provide candid and insightful comments on plan effectiveness and suggestions for Plan revision.

Since the Massachusetts Ocean Management Plan is the one of the first examples of marine spatial planning in the country, many groups are paying attention to the effectiveness of the planning process, enhancing the utility of this assessment. Also, prompted by the establishment of the National Ocean Policy in 2010, efforts are currently underway by the Northeast Regional Ocean Council, the Regional Planning Body, and others to develop a regional ocean plan to support ecosystem-based management of the Northeast's marine environment and its human uses. The recommendations that stem from this report could help with planning on a regional scale.

\footnotetext{
${ }^{1}$ From “Community Sustainability Engagement Evaluation Toolbox" website, http://evaluationtoolbox.net.au/index.php?option=com content\&view=article\&id=32\&Itemid=140
} 
Finally, it should be noted that, at the same time as CZM was drafting the Review and SeaPlan was conducting this assessment, a separate effort led by Mass Audubon was underway to create an extensive white paper to help inform the review process. Mass Audubon worked with Catherine Leland, a Harvard University John F. Kennedy School of Government student, to examine the Oceans Act of 2008 and implementation strategies. Ms. Leland interviewed many OAC members during her research in late 2012. The white paper is expected to be published by the summer of 2013 .

\section{Methodology}

To conduct this assessment, SeaPlan staff first conducted a literature review to better understand preferred methods of evaluation of similar ecosystem-based, spatial management plans. Because the Plan was finalized in 2010 and thus only had been implemented for about two years, SeaPlan recommended that the interviews acquire participants' perspectives on both the development and implementation processes associated with the Plan, rather than solely the direct outputs of the Plan, which were very limited at this stage of implementation. In consultation with CZM, SeaPlan staff designed an assessment approach that utilized a semi-structured interview ${ }^{2}$ to document advisory members' opinions. SeaPlan staff proposed that two main research questions be pursued: Is the $M A$ Ocean Plan progressing toward achievement of its objectives? and What are the opportunities to refine the MA Ocean Plan process?

\section{Assessment Team}

The SeaPlan assessment team consisted of four SeaPlan staffers playing a role in the assessment (Table 1).

Table 1: SeaPlan Assessment Team

\begin{tabular}{|l|c|c|c|c|}
\hline & Interviewer & Note Taker & Data Analysis & Data Coder \\
\hline Stephanie Moura & $\mathrm{X}$ & $\mathrm{X}$ & $\mathrm{X}^{\star}$ & \\
\hline Dave Kellam & $\mathrm{X}^{\star}$ & $\mathrm{X}$ & $\mathrm{X}$ & $\mathrm{X}^{\star}$ \\
\hline Kim Starbuck & & $\mathrm{X}^{\star}$ & $\mathrm{X}$ & $\mathrm{X}$ \\
\hline Kate Longley & & $\mathrm{X}$ & & \\
\hline
\end{tabular}

* Primary lead staff member

\footnotetext{
${ }^{2}$ Semi-structured interviews are a qualitative method of inquiry that combines a pre-determined set of open questions (questions that prompt discussion) with the opportunity for the interviewer to explore particular themes or responses further. A semi-structured interview does not limit respondents to a set of pre-determined answers (unlike a structured questionnaire). Semi-structured interviews are used to understand how processes work and how they could be improved; and allows respondents to raise unexpected issues.
} 


\section{Assessment Team Roles}

- Interviewer- Followed the interview script and clarified or explored issues and comments as they arose.

- Note Taker - A second SeaPlan staffer on the telephone during the interview that was typically silent and dedicated to the task of taking notes and in many cases transcribing key comments.

- Data Analysis - A person who participates in a group meeting to review interview dataset, identify themes and develop conclusions stemming from the data.

- Data Coder - A person who characterizes responses and codes them in an Access database for analysis.

\section{Survey Participants}

SeaPlan staff worked with CZM to select an appropriate list of current and former advisory members. For the OAC, CZM provided a list of 18 members, of which SeaPlan was able to interview 12 (67\%). Of the 8 SAC members provided by CZM, SeaPlan interviewed all 8 (100\%). Of the 20 interviews conducted, Dave Kellam (Communications Manager) conducted 16 (80\%) and Stephanie Moura (Executive Director) conducted 4 (20\%). A second SeaPlan staff person also silently listened to the interviews and took notes (see Table 1).

While the OAC and SAC members received regular updates on Plan implementation, most members are occupied with other responsibilities, making it understandably difficult for members to be knowledgeable of all the details of Plan development and implementation. Also, some OAC and SAC members are new appointees and were not involved in the development process of the Plan. Because of this, CZM staff provided OAC and SAC members with a Preliminary Draft of the document "Review of the Massachusetts Ocean Management Plan" (not including Section 4, which is meant to contain the results from the OAC/SAC interviews), for their review prior to the interviews. The team recommended that OAC and SAC members review this document to provide them with the background needed for an effective and efficient interview process. To gauge survey participants' level of understanding of the Plan, the first question of every interview asked participants how much of the document they were able to read.

\section{Interview Procedure}

SeaPlan staff conducted all the interviews over the phone, though an in-person option was available. Interviews were intended to last approximately 45 minutes, but in actuality, ranged from 20 to 1 hour and 6 minutes in duration. All participants agreed to allow the interviewer to record the conversation for accuracy, but one interview was not recorded due to technical issues. All interviews were anonymous to ensure privacy and candid responses.

SeaPlan staff developed an interview script that consisted of 12 questions, including questions related to the Plan development process, the final Plan promulgated in 2010, implementation of the Plan, and advisory members' involvement in planning processes, and preparation for a future revision of 
the Plan (Appendix 1). During the interview, both the interviewer and note taker took detailed notes on responses to these questions.

\section{Data Analysis}

The semi-structured interview enabled interviewers to collect data and subsequently code responses based on common reoccurring themes. This is a standard approach to analyze interview data. ${ }^{3}$ Coded responses could then be easily grouped, sorted and cross-referenced in the Microsoft Access database. To screen for significant themes that deserved analysis, SeaPlan staff grouped and summed the codes and then weighed the response rate by calculating the percentage of the total response count per theme code (Table 2 in Results).

It should be noted that not all codes could be screened in this way. Theme codes that were directly a result of prompting by interviewers were omitted, such as "Public/ Stakeholder Input" and "Administrative Process".

\section{Limitations}

Because a number of OAC members were not available for an interview, the data may not fully represent the perceptions of public officials.

\section{Results}

The following results section presents the interview data in three ways: responses by question, responses by theme, and noteworthy responses. The discussion section that follows will include analyses supported by a combination of findings from these groups.

\section{SLICE ONE: Responses by Questions}

SeaPlan staff asked every interviewee the same set of questions to facilitate discussion, with some questions being closed-ended and others designed to initiate a discussion on a topic. The results that follow were gleaned from response notes taken during the interview. For closed-ended questions, the responses are simply totaled. The assessment team also felt it was important to understand the context of the interview when considering the responses.

Interviewers read the interview script (Appendix 2) to OAC and SAC members and followed the interview protocol described in the methodology section.

\footnotetext{
${ }^{3}$ From Gorden, Raymond (1992). "Coding Interview Responses” from Basic Interviewing Skills. Itasca, IL: F. E. Peacock http://www.indiana.edu/ educy520/sec5982/week_5/qual_data_analy_ex2.pdf
} 
Question 1: Did you read the draft Plan Assessment recently sent to you by CZM? Of the 20 respondents who answered this question, 10 (50\%) said yes, 6 (30\%) said skimmed it, 4 (20\%) said no.

\section{Question 2: Describe your overall impression of the MA Ocean Management Plan} development process; what worked well, or could have been improved?

Regarding "what was exceptional about the development process", the most common positive responses were associated with administrative execution and public/stakeholder engagement. Advisory members were complimentary of the way CZM conducted the process, describing that the CZM staff was very good at moving the process forward. This sentiment was conveyed by one respondent saying "The team did remarkable job of staying true to its mission ... anchoring themselves in the legislation and guiding principles. That was helpful to me and commission members". Another respondent simply said "CZM staff was amazing." Outreach to stakeholders was also praised and was described by a number of interviewees as "exceptional" and "excellent". The topic of data acquisition during the planning process elicited positive comments about the data quality and general approval of the process, with the caveat that the timeframe was short.

Every interviewee was asked prompting questions about their opinion of advisory member knowledge of the ocean management options available identified during the process. This question required explanation and interviewees in general seemed confused. Most interviewees reported they were satisfied with the management options presented to them. A few interviewees reported they felt that their role was not to provide management options for consideration, but to refine and help implement the approaches CZM staff had selected and in some cases the legislation required.

Suggestions for improvement of the Plan development process varied more among interviewees than the positive responses, with most suggestions centering on not having adequate time for the development process, administrative challenges with needing to schedule meetings with more advanced notice and maintaining communication with all advisory members either through email or announcements through media like CZ-mail.

One respondent commented that the short timeframe dictated by the legislation was actually "genius", forcing CZM and others to move the process along and develop a plan in a timely manner. The respondent emphasized the point by saying that without the tight deadline, the Plan might not have been completed.

\section{Question 3: What is your overall impression of the final Plan - exceptional areas, opportunities for improvement?}

Overall, positive comments were related to the administrative process, highlighting that the framework was sound and "a good start". Wind energy siting was discussed relatively often, either noting that the Plan was a step towards enabling wind energy or avoiding negative issues with siting 
wind farms, such as those associated with the Cape Wind project. Suggestions for improvement were variable, although the issue of the Ocean Trust was cited by several respondents who desired clarity in how the funds will be administered and disbursed.

\section{Question 4: Broadly speaking, were your "interests" addressed in the Plan?}

Of the 18 respondents who answered this question, 14 (78\%) said yes, 1 (5\%) said somewhat, 3 (17\%) said no. Those that said "no" noted that the Plan had not addressed consistency with other state and federal activities, ocean literacy issues and climate change adaptation.

\section{Question 5: Do you feel the Plan has been implemented effectively??}

Of the 19 respondents who answered this question, 11 (58\%) said yes, 1 (5\%) said somewhat, 7 (37\%) said he/she did not know. Most of the positive comments referred to the permitting process, specifically referring to the effective permitting process of the Comcast/NSTAR cable project. Several interviewees noted that this project was an excellent example of successful implementation. Other respondents were unwilling to offer an opinion on implementation, saying that it was too early in the process to determine effectiveness.

\section{Question 6: What parts of the updating process do you think are working well or could be improved?} The majority of the positive responses to the updating process cited recent data products being developed, most notably the benthic habitat data. Through a prompted question, interviewees were asked to comment on interagency coordination aspects of the updating process and most reported positively, typically noting that increased interagency communication facilitated better coordination. Suggestions for improvement to the updating process related primarily to identifying clear goals and management priorities for the Plan and ensuring timely and informative communication about the updating activities.

\section{Question 7: Do you think the Plan has improved the permitting process?}

Of the 19 respondents who answered this question, $6(32 \%)$ said yes, 4 (21\%) said somewhat, 0 (0\%) said no and 9 (47\%) said "I don't know". A third of the respondents reported that they believed the permitting process was working and they typically felt strongly about this conviction. Many of those people said they believed the Plan improved governmental transparency and provided applicants clearer direction. Nearly half of the respondents were not comfortable with commenting on how the permitting process has been changed, citing most often their lack of time to keep up to date with the process.

\section{Question 8: Do you feel you have adequate information and opportunities to know what is going on with the Plan?}

Of the 20 respondents who answered this question, 17 (85\%) said yes, 1 (5\%) said somewhat, 2 (10\%) said no. Responses indicate that typically OAC and SAC members feel that they have excellent opportunities to be engaged in the process, and noted that communication about the process is very good. Suggestions for improvement were few, mostly focusing on improved electronic 
communication such as more timely and informative email notices, website updates, and production of an e-newsletter.

\section{Question 9: How often do you feel the OAC or SAC should meet?}

Of the 19 respondents who answered this question, 11 (58\%) said "quarterly", 6 (31\%) said "twice a year", 2 (11\%) said" as needed". When asked for suggestions on how to improve the meetings, responses were mostly about the structure of the meetings and communication supporting the meetings. Specifically a number of respondents, mostly in the SAC, called for clarity on the goals of the meetings and Plan, and a prioritization of data gaps to fill in the Plan. Logistical suggestions to improve the communication around the meetings included updating and improving CZM website information, video presentations on some topics for stakeholder groups to share and encourage board member communication by scheduling more agenda time for discussion.

Early in the interview process, an SAC member suggested the use of a webinar for meetings. The SeaPlan assessment team decided to include this concept as a prompting question when appropriate and asked about half of the participants if webinars could occasionally be used instead of in-person meetings. About half of those asked felt that webinars could be effective if the meeting was altered to work with a webinar. The others felt either that webinars were not as effective as the face-to-face interaction needed at the meetings or suggested offering every other meeting as a webinar. Interestingly, distance needed to travel to Boston did not seem strongly related to attitudes towards a webinar broadcast for the OAC or SAC meetings.

\section{Question 10: The Plan has science \& data priorities. Do you feel the state and partners} have made adequate progress these?

In general, interviewees were not able to say how all of the science and data priorities were being met in the Plan and eight (40\%) responded clearly that they did not know enough to comment on any of the science and data priorities. It was unclear from the responses as to why this was the case.

Respondents who did have an opinion on the issue would most often cite the benthic habitat data, and to a lesser extent recreational boating data as evidence that progress was being made. Most interviewees could not recall many of the priorities listed in the Plan, but instead focused on areas currently being updated, such as benthic habitat classification. Some respondents identified sand mining, migratory birds, visual impacts, and climate change as issues and/or data that should be included in the upcoming Plan revision.

\section{Question 11: During the revision process, what opportunities do you see to improve the Plan?}

There was a relatively strong recommendation to address climate change issues from advisory members and to better coordinate and evaluate state wind energy areas in the context of federal wind energy development areas. A relatively large number of participants affirmed the importance of updating and improving data as an overall part of the Plan revision process. A few respondents suggested that the revised plan should include a connection to regional ocean planning efforts. 


\section{Question 12: Do you have suggestions for improving the revision process?}

Suggestions were quite diverse although relatively large number of responses centered on stakeholder communication and goal setting. In general, respondents recommended stakeholder engagement efforts similar to those during the Plan development process for the revision process; although a few people cautioned that stakeholder desire and effort to work on the Plan revision may be less than during creation of the original Plan. A number of respondents urged that CZM develop clear goals for the Plan revision, among which should include prioritization of data gaps to be filled. One respondent suggested that the revision document include a side-by-side comparison of the original Plan and highlighted changes in the revised Plan to clearly identify what has changed and why.

\section{SLICE TWO: Responses by Themes}

In the previous section, the responses were grouped by question, which places them in the context of the interview, thus aiding reporting of specific concepts. This type of analysis is especially useful when summarizing closed ended questions or interpreting perceptions about specific topics. However, to assess the collective attitude regarding the research question "Is the MA Ocean Plan progressing toward achievement of its objectives?", it is useful to examine responses across the entire dataset. This crosscut analysis can yield unexpected insights and reveal themes that may warrant further investigation.

It is important to note that the response frequency data in Table 2 merely suggest likely significant themes and do not in isolation provide definitive information on OAC and SAC perceptions. To further clarify how these coded responses were distributed among the 20 interviewees, Table 1 lists the $\%$ of interviewees that gave a response to that theme code. This cross-cut screening process, coupled with the standard deviation of the interviewee commenting, is a better way to indicate significant themes than simple frequency counts.

To focus the analysis, the assessment team chose to examine themes with both a relatively high count rates $(>6.5 \%)$ and relatively high percentage of interviewees commenting. Below are the top five themes selected for primary analysis and four themes selected for secondary analysis using this crosscut screening process. 
Table 2: Theme codes that were not prompted during interviews, sorted by response frequency

\begin{tabular}{|c|c|c|c|c|c|}
\hline & & & \# of & & \\
\hline & Response & & Interviewees & $\%$ of Interviewees & Standard \\
\hline Theme Codes & Count & Response \% & Commenting & Commenting & Deviation ${ }^{\star}$ \\
\hline
\end{tabular}

\begin{tabular}{|c|c|c|c|c|c|}
\hline Communication & 34 & $9.1 \%$ & 18 & $90 \%$ & 1.22 \\
\hline Limited Time & 26 & $7.0 \%$ & 11 & $55 \%$ & 1.19 \\
\hline Goals & 25 & $6.8 \%$ & 8 & $40 \%$ & 1.35 \\
\hline Implications Beyond MA & 25 & $6.8 \%$ & 11 & $55 \%$ & 1.35 \\
\hline Wind Energy & 24 & $6.5 \%$ & 11 & $55 \%$ & 1.10 \\
\hline Accessible/transparency & 18 & $4.9 \%$ & 9 & $45 \%$ & 0.87 \\
\hline Climate Change & 18 & $4.9 \%$ & 7 & $35 \%$ & 2.57 \\
\hline Benthic/ Habitat & 17 & $4.7 \%$ & 7 & $35 \%$ & 1.27 \\
\hline SSU & 17 & $4.7 \%$ & 10 & $50 \%$ & 0.67 \\
\hline Evaluation & 15 & $4.1 \%$ & 7 & $35 \%$ & 1.86 \\
\hline Fisheries & 15 & $4.1 \%$ & 9 & $45 \%$ & 0.71 \\
\hline Few Projects Reviewed & 14 & $3.8 \%$ & 7 & $35 \%$ & 1.11 \\
\hline Comcast Cable Project & 12 & $3.3 \%$ & 8 & $40 \%$ & 0.76 \\
\hline Recreational Boating & 10 & $2.7 \%$ & 7 & $35 \%$ & 0.79 \\
\hline Adaptive & 9 & $2.5 \%$ & 6 & $30 \%$ & 0.55 \\
\hline Coastal, Land, Estuaries & 8 & $2.2 \%$ & 5 & $25 \%$ & 0.55 \\
\hline Cumulative Impacts & 7 & $1.9 \%$ & 6 & $30 \%$ & 0.41 \\
\hline Marine Mammals & 7 & $1.9 \%$ & 4 & $20 \%$ & 0.96 \\
\hline MOP/SeaPlan/GBMF & 7 & $1.9 \%$ & 4 & $20 \%$ & 1.50 \\
\hline Regulations & 7 & $1.9 \%$ & 4 & $20 \%$ & 0.50 \\
\hline Oceans Trust Fund & 7 & $1.9 \%$ & 6 & $30 \%$ & 0.50 \\
\hline Balance Development \& Protection & 6 & $1.6 \%$ & 4 & $20 \%$ & 0.58 \\
\hline Ecosystem & 6 & $1.6 \%$ & 3 & $15 \%$ & 1.00 \\
\hline Meeting Locations(outside Boston) & 6 & $1.6 \%$ & 4 & $20 \%$ & 0.58 \\
\hline Oceans Trust Fund & 6 & $1.6 \%$ & 5 & $25 \%$ & 0.50 \\
\hline Protection & 5 & $1.4 \%$ & 4 & $20 \%$ & 0.50 \\
\hline Oceans Act of 2008 & 4 & $1.1 \%$ & 3 & $15 \%$ & 0.50 \\
\hline Local Control & 4 & $1.1 \%$ & 2 & $10 \%$ & 0.58 \\
\hline Money a limiting factor & 4 & $1.1 \%$ & 4 & $20 \%$ & 1.41 \\
\hline Too early to tell & 4 & $1.1 \%$ & 2 & $10 \%$ & 0.00 \\
\hline Sand Mining & 4 & $1.1 \%$ & 3 & $15 \%$ & 0.58 \\
\hline Birds & 4 & $1.1 \%$ & 4 & $20 \%$ & 0.00 \\
\hline
\end{tabular}

*Standard Deviation indicates the extent of deviation for a group as a whole, i.e. the lower the standard deviation, the more evenly distributed the responses are among interviewees. For example, in the table above four interviewees provided the same number of responses coded "Birds" - thus the standard deviation is 0 . In contrast, most of the seven people who provided responses coded "Climate Change" only mentioned it once, except one person mentioned it eight times during the interview - thus the standard deviation is 2.57 . 


\section{Communication}

Communication about the Plan and during the planning process was identified by interviewees as an important component. Many interviewees noted that CZM did an excellent job communicating during the development process. One OAC member said "As a commission member, we could always connect the dots to efforts.... [Information] was always very understandable, thorough, made sense, [and] always had a context to it." A number of interviewees noted that communication could be improved during the updating process. One OAC member said "If we had more press releases and media coverage - that would be helpful. Do people know the plan is being updated?" Others suggested more outreach on new data products.

\section{Goals}

A striking number of responses from the SAC were focused on goal setting and the related notion that indicators need to be established, evaluated and monitored. SAC member responses included "What affects the food chain? How do we look at information for decision making? We should think more about the end game" and "They should define the process for the meetings. Put someone in charge, develop goals and missions. What is the purpose of the SAC?" Interestingly, only one OAC member referenced indicators in a response.

\section{Implications beyond $M A$}

References to regional or federal marine spatial planning were noted occasionally. Often the Plan was praised for being a model for other efforts. Suggestions on how to improve the Plan process were related to coordinating the state with regional systems and management initiatives.

\section{Limited Time}

Pervasive in nearly every response was the caveat that time was a limiting factor or the timeframe was too short to expect that sufficient evaluation outcomes could be created. Time was a significant factor for the development process, but also appeared relatively often when respondents discussed the Plan itself, e.g. “The Plan was really a great document created in a short period of time.” Allowing for enough time was also mentioned in a number of suggestions for the revision process.

\section{Accessibility/Transparency}

Positive responses associated with accessibility to the process and data, as well as transparency of the process, were prevalent in discussions of the development process, final plan and permitting. In general, advisory members gave widespread praise for the transparency of the process. A number of OAC and SAC members noted that transparency must be maintained during implementation and revision.

\section{Wind Energy}

Wind energy issues were most often mentioned as being adequately addressed in the Plan, especially compared to the pre-Plan conditions in place when the Cape Wind project was proposed. There were several suggestions on how to improve the treatment of wind energy in the Plan, such as 
determining if commercial wind areas are multi-use, eliminating provisional wind areas and clarifying local, state, and federal jurisdiction of wind energy areas. Some interviewees expressed disappointment at the lack of proposed wind projects since the Plan's promulgation and that the Plan did not go far enough in defining viable wind areas, as evidenced by one interviewee saying "I was disappointed at the end of everything, we only defined $2 \%$ of state waters that could support renewable energy."

\section{Climate Change}

The issue of climate change was prevalent in responses from a relatively sizable group of respondents, especially when suggesting how to improve the Plan during the revision process. These respondents tended to have either a scientific background or a coastal community resiliency perspective. In general, climate change was viewed as an overarching factor that needed to be accounted for in every aspect of the planning process.

\section{Benthic Habitat}

A number of participants praised CZM for the "excellent" progress being made with seafloor mapping in the planning area. On the other hand, a few participants noted that the term, "hard and complex seafloor", still needs to be defined. Furthermore, one participant commented that the process for integrating hard complex seafloor data into the Plan is currently unknown, and more outreach to share the seafloor data with stakeholders and experts should be conducted.

\section{SSU}

Overall, interviewees were positive about the establishment of Special, Sensitive, Unique Areas (SSUs) and the ability of SSUs to accommodate multiple uses. When interviewees suggested improvements to SSUs, most favored better delineation of areas and clarification of approved uses. Several interviewees noted that SSUs should be strengthened through regulation. 


\section{SLICE THREE: Noteworthy Responses}

During the course of the interviews, occasionally one or a few respondents would make a suggestion or provide insight that seemed noteworthy to the interviewer. Even though these types of responses did not stand out in the frequency analyses of coded themes, the assessment team felt that the responses warranted mention.

\section{Expand the area of the Plan}

The Massachusetts Oceans Act of 2008 has been called a "blue water plan", addressing the planning area between 0.3 miles from shore out to 3 miles. Five respondents expressed interest in expanding the planning area to include near shore areas. Reasons to expand the area were either directly development-based (aquaculture siting and energy infrastructure connectivity with offshore generation) or ecosystem management-based (water quality management).

\section{Mitigation}

A small, but adamant subset of respondents noted that they were very interested in the details of the Ocean Trust and how mitigation funds will be allocated. One interviewee said "We need transparency on the criteria and disbursement of Ocean Trust Fund" and another said "I would like to see a closer connection between this Plan and the subcommittees that are looking at mitigation for the MA coast water."

\section{Fisheries Management}

Eight respondents made a total of ten comments about the issue of fisheries management as it relates to the Plan. This issue may warrant further investigation since fisheries management in the Plan was a lively topic during the early stages of Plan development. A subset of the fisheries management responses indicated that the Plan has had little to no impact on the fisheries management, but they did not feel this was a problem. Another subset, however, felt Plan implementation was lacking in this area and that little integration had occurred, with most referencing the related language in the Act that notes fisheries management plans "shall be integrated, to the maximum extent practicable, with an ocean management plan." A few felt that the issue should be revisited during the amendment process. One respondent said "One of the areas that needs discussion is implications of fishing, without violating the statue where fisheries is in the hands of DMF."

\section{Evaluation Bias}

Overall, evaluation bias did not appear to be a concern of OAC or SAC members. There were two interviewees that questioned the role of CZM as the lead author of the Review. One person said "Should be a third party assess the Plan vis-à-vis stated goals?", and another said "Authors of the document [Review] were also judging the direction of the decisions. Conflict of interest? Perhaps Science Council members should have written it." 


\section{Exploration of Innovative Ocean Uses}

One interviewee noted that the Plan revision should accommodate emerging technologies and said "The ocean economy and activities taking place on ocean through marine science and technology are barreling forward. . . Biomimicry, green chemistry, robotic tuna, ... There are so many ocean opportunities as world changes. The Plan will have to keep up with that.” 


\section{Other Issues}

A number of other noteworthy issues or specific suggestions were mentioned by one or two people. They were:

- Collect data on visual impacts

- Incorporate ocean literacy

- Focus on aquaculture data and sites

- Incorporate more cultural resources data

- CZM should research a Center for Coastal Studies grant to do survey near shore areas

- The Martha's Vineyard wind area - who designates use, Martha's Vineyard Commission or the State?

- Do maps in the Plan or data collected by project proponents take precedence? Does CZM adopt the project proponent data?

- CZM should address the issue of redefining complex hard complex bottom data layer; (e.g., should CZM include slipper shell reefs, pilings, and worms?)

- Examine the whole distribution network of cables. How do you support these sites in the future?

\section{Discussion}

In this section, the assessment team presents broader observations extrapolated from the three slice analysis approach of the interview data. Then a summary of conclusions and suggestions for further investigation are presented.

\section{Broader Observations}

\section{Plan implementation and performance}

$\mathrm{OAC}$ and SAC members understand that the Plan is a work in progress. Even though conceptually interviewees universally believe the plan's approach is sound, when pressed to comment on its performance, the majority of interviewees felt that the Plan has not been in place long enough or sufficiently tested to determine its effectiveness.

This perspective seems consistent with the way OAC and SAC members define Plan "implementation". While there is some variation, most interviewees consider ocean use permitting as a proxy for plan implementation, i.e. Plan performance was often described in relationship to project review and permitting. The view of outcomes as a measure of Plan performance is important to remember when communicating about the Plan and suggests that tangible stories about project applications are more effective than descriptions of process. This attitude was summed up by one interviewee who said, "A good plan should inform real decisions". 
It is worth noting, however, that a broader definition of implementation, to include carrying out the full range of actions set forth in the Plan, may offer additional benefits. For example, the Plan identified eight priority data needs, yet most respondents were not aware of these and whether there has been progress in filling these data gaps (with the exception of benthic habitat characterization and recreational boating information). Other examples might include the Plan's stated intent to sustain ongoing stakeholder engagement and to develop and promulgate implementing regulations. Using a broader definition of "Plan implementation", beyond reviewing and permitting specific ocean development proposals, suggests additional measures of plan performance that can be evaluated in the near-term and opportunity to communicate less obvious benefits of CMSP (e.g. improving the scientific basis for future ocean planning decisions).

\section{Drivers and Enabling Conditions}

Massachusetts' experience appears to demonstrate the significance of drivers to catalyze and sustain ocean planning initiatives. Interviewees pointed to one or more of three particular factors as essential conditions driving or enabling development of the Plan - a controversial offshore wind proposal, the state legislative mandate with a deadline and agency staff leadership. A few advisory members also cited availability of supplemental private resources as important for the state's success. As one interviewee described it "Without MOP [Massachusetts Ocean Partnership], this never would have been a stakeholder influenced process. It would have been a government process. MOP was essential."

These observations suggest that CMSP still needs momentum to overcome the inertia of status quo ocean management and highlight the importance of strategic situation analysis for Massachusetts going forward, other states, and broader regional ocean planning processes being initiated under the National Ocean Policy. Identifying key supporters and detractors and understanding time-sensitive opportunities and threats in an ever-evolving political and institutional landscape can help governmental and nongovernmental ocean planning leaders capitalize on key drivers and conditions to make CMSP the new norm.

\section{Communication Paradox}

A common phenomenon in public policy is the tendency for the public and stakeholders to pay attention mainly when a significant decision or action is imminent. In Massachusetts, helped by the novelty of CMSP and the short duration planning period, the state was able to sustain stakeholder engagement at a relatively high level. However, an interesting paradox appears when we look across $\mathrm{OAC}$ and SAC members' responses. While a vast majority of interviewees expressed satisfaction with opportunities to be engaged and with communication about the plan, a preponderance of OAC and SAC members also indicated that, since the plan's release, they have not kept up with it and/or have not heard much about it. In response to a question about the revision process, one interview said "I thought the first go around had more energy. There was commitment from the cabinet to get this thing done. Is that happening? It may be, but I don't know." Another responding to progress on science and data priorities said, "I would have liked to have a better sense on what was going on a 
regular basis, but maybe it was available and I wasn't aware." This raises a question about the optimal level of communication at different points in the ocean planning, implementation and revision processes and suggests the utility of an overall strategic communications framework that considers the cost-benefit of different levels of and vehicles for communication at different phases of the process.

\section{Summary of Conclusions}

Based on insights from the three slices of analysis and deeper discussions of the data, the SeaPlan evaluation team developed a list of general conclusions about the perceptions of the OAC and SAC about Plan performance and their suggestions for a future revision process (Table 3).

\section{Table 3: Conclusions}

OAC and SAC members appreciated the focused effort by CZM and partners to produce a quality plan responsive to specific Massachusetts conditions. Most members were keenly aware of the Plan's significance as the first plan of its kind in the nation and a model for other regions.

OAC and SAC members view CZM staff as very competent. OAC Commissioners and SAC Councilors are generally very satisfied with the Plan development and implementation.

Plan implementation and performance is interpreted primarily in terms of permitting outcomes, rather than administrative progress or progress on science and data priorities.

Administrative execution and communication during the planning process were seen as effective, attributable largely to the time-limited context for Plan development.

Maintaining this intense focus and engagement will be challenging as the Plan transitions from development to routine implementation.

Key issues of interest to OAC and SAC members for the Plan revision process include: climate change adaptation issues, further goals and indicators development, and integration with regional CMSP efforts.

$\mathrm{OAC}$ and SAC meeting structure and schedule is generally adequate, although certain improvements were suggested, including clearer communication of meeting objectives, longer-range scheduling, and increased interactions between the OAC and SAC through more intra-group and inter-group communications. Interest is limited in conducting meetings through a webinar option.

\section{Suggestions for Further Investigation}

The analysis of the interview data highlighted some shared perceptions among OAC and SAC members and revealed some areas worthy of deeper examination. Further analysis of the data may reveal more insights. For example, the data could be sorted by responses from OAC and SAC members to highlight differences between the two groups. Data could also be sorted by duration serving of the Commission or Council, thus illuminating opportunities and needs for new member orientation and knowledge transfer. 
To better answer the question of Plan performance, more assessment of those stakeholders directly affected by the plan would be useful. An assessment using a similar semi-structured interview approach would help characterize the experience of ocean developers, both those who were awarded permits under the Plan and those that were denied. Interviewing ocean developers early in their planning process and then again after completing the permitting process would yield valuable information on developer expectations and experiences. Interviews with the conservation and ocean research communities would also help inform Plan performance to see how they perceive the Plan impacting their work.

Crosswalking this analysis with other research would also improve overall understanding of Plan performance. Once Catherine Leland has completed her examination of the Oceans Act of 2008 and implementation strategies, it would be useful to synthesize the results of the two efforts and see if further insights emerge. 


\section{Appendices}

1. Survey Script

2. Complete List of Theme Codes

3. Acronyms and Glossary 


\section{Appendix 1: Survey Script}

Thank you for agreeing to be interviewed today,

The purpose of this interview is to document advisory board members' perspectives on the Mass Ocean Management Plan: from the development process, to implementation and updating, to help inform the future revision process.

The interview should take 45 minutes. Responses are confidential and will not be directly attributable to you. To help accurately document your comments, I would like to record this conversation. Is that ok with you?

\section{[If YES] Great, let's begin}

[If NO] No problem, I will not record the conversation, but please bear with me as I carefully take notes during our conversation.

\begin{tabular}{|c|c|c|}
\hline Main Questions & Prompting Questions & Interviewer Notes \\
\hline $\begin{array}{l}\text { 1.a.) Recently, MA CZM sent you a DRAFT } \\
\text { Plan Assessment. How much of it did you get a } \\
\text { chance to read? } \\
\text { 1. All or Most of it } \\
\text { 2. Skimmed it } \\
\text { 3. Did not read it }\end{array}$ & & \\
\hline $\begin{array}{l}\text { 2. a.) Describe your overall impression of the } \\
\text { MA Ocean Management Plan development } \\
\text { process; what worked well, or could have been } \\
\text { improved? }\end{array}$ & $\begin{array}{l}\text { [ if asked the dev. Process is from } 2008 \\
\text { through } 2010 \text { when the Plan finalized) } \\
\text { b). [if not identified] what are your } \\
\text { thoughts on: } \\
\text { 1. data acquisition process } \\
\text { 2. stakeholder engagement } \\
\text { 3. Options available to you when } \\
\text { considering management approach }\end{array}$ & $\begin{array}{l}\text { Note that often people end up } \\
\text { Giving the same response to } \\
\text { several answers. That is ok. }\end{array}$ \\
\hline $\begin{array}{l}\text { 3.) What is your overall impression of the final } \\
\text { Plan - exceptional areas, opportunities for } \\
\text { improvement? }\end{array}$ & & \\
\hline $\begin{array}{l}\text { 4.) Broadly speaking, were your "interests" } \\
\text { addressed in the Plan }\end{array}$ & & $\begin{array}{l}\text { If asked to clarify, say } \\
\text { "interests" can be of the seat } \\
\text { they represent or other } \\
\text { interests he/she represent. }\end{array}$ \\
\hline \multicolumn{3}{|l|}{$\begin{array}{l}\text { 5.) Do you feel the Plan has been implemented } \\
\text { effectively? }\end{array}$} \\
\hline $\begin{array}{l}\text { 6.a.) What parts of the updating process do } \\
\text { you think are working well or could be } \\
\text { improved? }\end{array}$ & $\begin{array}{l}\text { 6.b.) [if not identified] How effective is } \\
\text { the process to: } \\
\text { 1. integrate new data } \\
\text { 2. solicit expert guidance and } \\
\text { stakeholder input }\end{array}$ & $\begin{array}{l}\text { [if interviewee cannot come } \\
\text { up with example, prompt with } \\
6 \text { b. questions] }\end{array}$ \\
\hline
\end{tabular}




\begin{tabular}{|c|c|c|}
\hline & 3. improve interagency coordination & \\
\hline \multicolumn{3}{|l|}{$\begin{array}{l}\text { 7.) Do you think the Plan has improved the } \\
\text { permitting process? }\end{array}$} \\
\hline $\begin{array}{l}\text { 8.a.) Do you feel you have adequate } \\
\text { information and opportunities to know what is } \\
\text { going on with the Plan? }\end{array}$ & $\begin{array}{l}\text { [If Yes or No] } \\
\text { 8.b.) Suggestions to improve } \\
\text { opportunities or communication? }\end{array}$ & \\
\hline $\begin{array}{l}\text { 9.a.) To be effective, do you think the OAC } \\
\text { should meet: } \\
\text { - } \quad \text { About quarterly } \\
\text { - Twice a year } \\
\text { - Yearly } \\
\text { - As Needed }\end{array}$ & $\begin{array}{l}\text { 9.b.) Suggestions to improve meetings? } \\
\text { 9.c.) What do you think about webinars? }\end{array}$ & \\
\hline \multicolumn{3}{|l|}{$\begin{array}{l}\text { 10.a.) The Plan has science } \& \text { data priorities. } \\
\text { Do you feel the state and partners have made } \\
\text { adequate progress these? }\end{array}$} \\
\hline $\begin{array}{l}\text { 11.a.) During the revision process, what } \\
\text { opportunities do see to improve the Plan? }\end{array}$ & $\begin{array}{l}\text { [if not identified] } \\
\text { 11.b.) Opportunities for more data? } \\
\text { 11.c.) More stakeholder engagement? }\end{array}$ & \\
\hline $\begin{array}{l}\text { 12.a.) Do you have suggestions for improving } \\
\text { the revision process? }\end{array}$ & & $\begin{array}{l}\text { i.e., meeting structure, } \\
\text { approach, stakeholder } \\
\text { engagement? }\end{array}$ \\
\hline
\end{tabular}

That concludes the interview. Thank you for your time. We will summarize all interviews and provide it to MA CZM for inclusion in the final Plan Assessment. If you have questions at any time, feel free to call me (your name) at (your number).

Bye. 


\section{Appendix 2: Complete List of Theme Codes}

\begin{tabular}{|c|c|}
\hline Codes & Notes \\
\hline Accessibility/transparency & Access to information about the planning process \\
\hline Adaptive & The plan can change to accommodate new formation \\
\hline Administrative Execution & Knowledge of CZM, leadership, meeting management \\
\hline Administrative Process & e.g., structure, stakeholder meetings, review of data \\
\hline \multicolumn{2}{|l|}{ Balance Development and Protection } \\
\hline \multicolumn{2}{|l|}{ Benthic/ Habitat } \\
\hline Birds & includes migratory birds and seabirds \\
\hline Cape Wind & reference to the Cape Wind Project \\
\hline \multicolumn{2}{|l|}{ Climate Change } \\
\hline Coastal, Land, Estuaries & Land- sea interface \\
\hline \multicolumn{2}{|l|}{ Comcast Cable Project } \\
\hline Communication & Related to presentations, announcements and outreach \\
\hline \multicolumn{2}{|l|}{ Confusion/Unclear } \\
\hline \multicolumn{2}{|l|}{ Cumulative Impacts } \\
\hline Data Acquisition & Gathering data about different uses \\
\hline \multicolumn{2}{|l|}{ Data Quality } \\
\hline \multicolumn{2}{|l|}{ Ecosystem } \\
\hline \multicolumn{2}{|l|}{ Evaluation } \\
\hline Few Projects Reviewed & Refers to the three projects submitted for MA approval \\
\hline \multicolumn{2}{|l|}{ Fisheries } \\
\hline \multicolumn{2}{|l|}{ Goals } \\
\hline \multicolumn{2}{|l|}{ IDK/ Can't Say } \\
\hline \multicolumn{2}{|l|}{ Implications Beyond MA } \\
\hline \multicolumn{2}{|l|}{ Interagency } \\
\hline \multicolumn{2}{|l|}{ Limited Time } \\
\hline \multicolumn{2}{|l|}{ Local Control } \\
\hline \multicolumn{2}{|l|}{ Marine Mammals } \\
\hline \multicolumn{2}{|l|}{ Meeting Locations (outside Boston) } \\
\hline \multicolumn{2}{|l|}{ Money a limiting factor } \\
\hline MOP/SeaPlan/GBMF & Private-funded support for MSP \\
\hline \multicolumn{2}{|l|}{ Oceans Act of 2008} \\
\hline \multicolumn{2}{|l|}{ Oceans Trust Fund } \\
\hline \multicolumn{2}{|l|}{ Other issues (unique) } \\
\hline \multicolumn{2}{|l|}{ Permitting } \\
\hline \multicolumn{2}{|l|}{ Protection } \\
\hline \multicolumn{2}{|l|}{ Public/Stakeholders Input } \\
\hline \multicolumn{2}{|l|}{ Recreational Boating } \\
\hline Regulations & \\
\hline Sand Mining & includes beach nourishment \\
\hline SSU & special, sensitive, unique areas \\
\hline Too early to tell & \\
\hline Webinars & \\
\hline Wind Energy & \\
\hline
\end{tabular}

Total: 43 theme codes 


\section{Appendix 3: Acronyms and Glossary}

\section{Acronyms}

OAC: Ocean Advisory Commission

SAC: Science Advisory Council

CZM: Coastal Zone Management

NROC: Northeast Regional Ocean Council

CMSP: Coastal and Marine Spatial Planning

\section{Glossary}

Cape Wind Project: An offshore wind farm project proposed by private developer, Cape Wind Associates, on Horseshoe Shoal in Nantucket Sound off Cape Cod, Massachusetts.

Coastal and Marine Spatial Planning: Coastal and Marine Spatial Planning (CMSP) addresses a full range of human uses across sectors, is supported by credible science, incorporates public and user-group input, is adaptable to changing needs, and ultimately, supports sustainable marine industries and resilient ocean ecosystems.

National Ocean Policy: The 2010 Executive Order adopts a National Policy that includes a set of overarching guiding principles for management decisions and actions toward achieving the vision of "an America whose stewardship ensures that the ocean, our coasts, and the Great Lakes are healthy and resilient, safe and productive, and understood and treasured so as to promote the well-being, prosperity, and security of present and future generations."

Ocean Advisory Commission: Established by the Oceans Act of 2008 in the following section:

(c)(i) There shall be an ocean advisory commission to assist the secretary in developing the ocean management plan. The commission shall consist of 3 members of the senate, 1 of whom shall be appointed by the minority leader of the senate; 3 members of the house of representatives, 1 of whom shall be appointed by the minority leader of the house of representatives; the director of coastal zone management or his designee; the director of marine fisheries or his designee; the commissioner of environmental protection or his designee; and 8 members to be appointed by the governor, 1 of whom shall be a representative of a commercial fishing organization, 1 of whom shall be a representative of an environmental organization, 1 of whom shall have expertise in the development of offshore renewable 
energy, 1 of whom shall be a representative of the Cape Cod commission, 1 of whom shall be a representative of the Martha's Vineyard Commission, 1 of whom shall be a representative of the Merrimack Valley Planning Commission, 1 of whom shall be a representative of the metropolitan area planning council and 1 of whom shall be a representative of the Southeastern Regional Planning and Economic Development District. Members shall be appointed for terms of 3 years, except that, initially, 4 members appointed by the governor shall be appointed for terms of 2 years and 3 members appointed by the governor shall be appointed for terms of 1 year. The appointing authority may fill any vacancy that occurs in an unexpired term. The members of the commission shall be selected with due regard to coastal geographic distribution. The Act required that the OAC would meet at least quarterly, hold public meetings and make recommendations to the Secretary of Environmental Affairs with the technical support of the Office of Coastal Zone Management and Division of Marine Fisheries.

Ocean Resources and Waterways Trust Fund: The Trust will receive all proceeds from ocean development mitigation fees as well as appropriations or other credits.

Ocean Science Advisory Council: Established by the Oceans Act of 2008 and in the following section:

(d) There shall be an ocean science advisory council to assist the secretary in creating a baseline assessment and obtaining any other scientific information necessary for the development of an ocean management plan. The council shall consist of 9 members to be appointed by the secretary, 3 of whom shall be scientists from academic institutions, at least 1 of whom shall be from the School for Marine Science and Technology at the University of Massachusetts at Dartmouth and at least 1 of whom shall be from the Department of Environmental, Earth and Ocean Sciences at the University of Massachusetts at Boston; 3 of whom shall be scientists from private, nonprofit organizations, at least 1 of whom shall be a scientist designated by the Massachusetts Fishermen's Partnership; and 3 of whom shall be scientists from government agencies with demonstrated technical training and experience in the fields of marine ecology, geology, biology, ichthyology, mammalogy, oceanography or other related ocean science disciplines, at least 1 of whom shall be from the division of marine fisheries. The secretary shall serve as coordinator of the council.

Oceans Act: Governor Deval Patrick signed the Oceans Act on May 28, 2008, requiring the Secretary of Energy and Environmental Affairs (EEA) Ian Bowles to develop a comprehensive ocean management plan, with a draft plan by June 30, 2009, and a final plan promulgated by December 31, 2009.

Plan implementation: The execution of the 2009 Massachusetts Ocean Management Plan.

Provisional wind areas: Three potential commercial-scale wind areas that passed the exclusionary screening process but appear to have potentially more significant technical limitations, cumulative impacts, and/or less suitability for wind energy. 
Regional Planning Body: The Regional Planning Body consists of federal, state, and tribal representatives and they are tasked with developing regional goals, objectives, and ultimately regional CMS plans.

Semi-structured Interviews: Semi-structured interviews are a qualitative method of inquiry that combines a pre-determined set of open questions (questions that prompt discussion) with the opportunity for the interviewer to explore particular themes or responses further. A semi-structured interview does not limit respondents to a set of pre-determined answers (unlike a structured questionnaire). Semi-structured interviews are used to understand how processes work and how they could be improved. It also allows respondents to discuss and raise issues that the interviewer may not have considered.

Stakeholders: A person, group, organization, member, or system who can be affected by the results of that in which they have a stake. 